\title{
VERZEICHNIS DER DOKUMENTE
}

\section{KAPITEL I}

Die Abkommen der Alliierten wäbrend des zweiten Weltkrieges über die gemcinsame Besetzung und Verwaltung Berlins

1. Protokoll zwischen den Vereinigten Staaten, Großbritannien und der Sowjetunion vom 12. September 1944 über die Besatzungszonen in Deutschland und dic Verwaltung von Groß-Berlin . . . . . . . . . . . . . .

2. Abkommen 2 wisden den Vereinigten Staaten, Großbritannien und der Sowjetunion vom 14. November 1944 über Ergänzungen zu dem Protokoll vom 12. September 1944 über dic Besatzungszonen von Deutschland und dic Verwaltung von Groß-Berlin (Auszug) . . . . . . . . . . . . . . . . . .

3. Londoner Abkommen vom 14. November 1944 über dic Kontrolleinrichtungen in Deutschland in der durch das Erfänzungsabkommen vom 1. Mai 1945 über den Beitritt der Französischen Republik abgeänderten Fassung (Auszug) . . . . .

4. Bericht über die Krim-Konferenz (Jalta-Konferenz) vom 12. Februar 1945 (Auszug)

5. Protokoll über die Verhandlungen auf der Krim-Konferenz (Jalta-Konferenz) (Am 24. März 1947 durch das amerikanische Außenministerium der Presse übergeben) (Auszug) . . . . . . . . . . . . . . . .

\section{KAPITEL II}

Die Einnabme Berlins durch die Rote Armee und die Neubildung der städtischen Selbstverwaltung

6. Befehl Nr. 1 des Chefs der sowjetischen Besatzung der Stadt Berlin vom 28. April 1945 (Auszug) . . . . . . . . . . . . . .

7. Bckanntmachung rom 16. Mai 1945 über die Bildung einer Berliner städtischen Selbstverwaltung (Auszug) . . . . . . . . . . . . .

8. Bekanntmachung des Oberbürgermeisters der Stadt Berlin vom 17. Mai 1945 über die Bildung des Magistrats der Stadt Berlin (Auszug) . . . . . . . . . .

9. Befehl Nr.1 der sowjetischen Militärverwaltung in Deutschland (SMA) vom 9. Juni 1945 über die Organisation der Militärverwaltung zur Verwaltung der sow jetischen Besatzungszone in Deutschland .............

\section{KAPITEL III}

Die Ubernabme der obersten Regierungsgewalt in Deutschland durch die Alliierten

10. Erklärung in Anbetracht der Niederlage Deutschlands und der Obernahme der obersten Regierungsgewalt in Deutschland durch die Regierungen der Vereinigten Stazten, Großbritanniens, der Sowjetunion und durch die provisorische Regierung der Französischen Republik vom 5. Juni 1945 (Auszug) . . . . . . . . 
11. Feststellung seitens der Regierungen Großbritanniens, der Vereinigten Staaten und der Sowjetunion sowie der Provisorischen Regierung der Französischen Republik über das Kontrollverfahren in Deutschland vom 5. Juni 1945 (Auszug)

12. Feststellung seitens der Regierungen Großbritanniens, der Vereinigten Staaten und der Sowjetunion sowie der Provisorischen Regierung der Französischen Republik über die Besatzungszonen in Deutschland vom 5. Juni 1945 (Auszug)

\section{KAPITEL IV}

\section{Die Einridhtung der Viermächte-Besetzung und -Verwaltung Berlins}

13. Ersuctien des Oberbefchlshabers der anglo-amerikanischen Strcitkräfte, General Eisenhower, vom 2. Juni 1945 an die Vereinigten Stabschefs . . . . . . .

14. Weisung der Vereinigten Stabschefs an General Eisenhower, genehmigt durch Präsident Truman am 3. Juni 1945 . . . . . . . . . . . . . . 13

15. Bricfwectsel 2wischen Präsident Truman und Generalissimus Stalin vom Juni 1945 über den Einzugstermin der westlichen Alliierten in Berlin (Auszüge) . . . 13

A. Truman an Stalin, erhalten am 15. Juni $1945 \ldots \ldots 13$

B. Stalin an Truman, 16. Juni $1945 \ldots \ldots 13$

C. Truman an Stalin, erhalten am 19. Juni 1945 ... . . . . . . . . . 14

16. Beschluß der Konferenz von Vetretern der Alliierten Oberkommandos vom 7. Juli 1945 über die gemeinsame Verwaltung Berlins . . . . . . . . . . .

17. Kommuniqué der Konferenz von Vertretern der Alliierten Oberkommandos vom 10. Juli 1945 über die Shaffung einer Interalliierten Militärkommandantur für Berlin (Auszug) . . . . . . . . . . . . . .

18. Befehl Nr. 1 der Alliierten Kommandantur der Stadt Berlin vom 11. Juli 1945

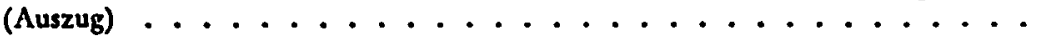
13

19. Abkommen zwischen den Regierungen Großbritanniens, Frankreichs, der Vereinigten Staaten und der Sowjetunion vom 26. Juli 1945 über die Ergänzung des Protokolls vom 12. September 1944 über die Besatzungszonen von Deutschland und die Verwaltung von Groß-Berlin (Auszug) ............

20. Kommuniqué der 4. Sitzung der Alliierten Kommandantur der Stadt Berlin vom 1. August 1945 (Auszug) . . . . . . . . . . . . .

\section{KAPITEL V}

Das Potsdamer Abkommen vom 2. August 1945

21. Mitteilung über die Dreimähtekonferenz von Berlin vom 2. August 1945 (Auszug)

\section{KAPITEL VI}

\section{Berlin unter Viermüchteverwaltung}

22. Proklamation Nr. 1 des Alliierten Kontrollrats vom 30. August 1945 zur Obernahme der obersten Gerralt in Deutschland . . . . . . . . . . .

23. Bezirksverfassungsstatut der Stadt Berlin vom 10. Oktober 1945 (Auszug) . . .

24. Richtlinien über die Aufgaben der Alliierten Komandantur der Stadt Berlin, vorgeschlagen am 27. November 1945 und vom Alliierten Koordinierungsaus-

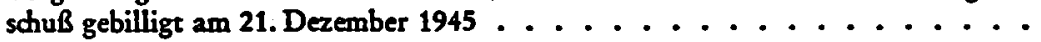


25. Anordnungen der Alliierten Kommandantur der Stadt Berlin zur Stellung des Magistrats gegenüber der Reichspost (BK/O [45] 170 und BK/O [46] 431) . . . 30

26. Anordnung der Alliierten Kommandantur der Stadt Berlin vom 21. Januar 1946 über den räumlichen Geltungsbercich von Gesetzen und Verordnungen . . . . . 31

27. Vorläufige Verfassung von Groß-Berlin vom 13. August 1946 . . . . . . . . 32

A. Schreiben der Alliierten Kommandanten an den Oberbürgermeister (BK/O [46] 326) ........................ 32

B. Vorläufige Verfassung von Groß-Berlin vom 13. August 1946 (Auszug) . . . 32

C. Schreiben an den Oberbürgermeister vom 31. Januar 1947 über die Bestätigung von Gesetzen (BK/O [47] 34) . . . . . . . . . . . . 35

D. Schreiben an den Oberbürgermeister vom 28. Februar 1947 über .Leitende Personen der Stadtverwaltung" (BK/O [47] 56) . . . . . . . . . 36

28. Kontrollratsgesetz Nr. 46 über die Auflösung des Staates Preußen vom 25. Fcbruar 1947 (Auszug) . . . . . . . . . . . . . 37

\section{KAPITEL VII}

Verhandlungen und Vereinbarungen der Alliierten über die Verbindungslinien zwischen Berlin und Westdeutschland

29. Bemerkungen des Feldmarschalls Montgomery über die Konferenz der Vertreter der Alliierten Oberkommandos am 29. Juni 1945 in Berlin (Auszug) . . . .

30. Bemerkungen General Clays über die Verbindungslinien der westlichen Alliierten nach Berlin und die Konferenz vom 29. Juni 1945 (Auszug) . . . . . . . . 38

31. Sitzungskommuniqués des Alliierten Kontrollrats und des Koordinierungskomitees (10. August 1945 - 7. Februar 1946) . . . . . . . . . . . .

A. Kommunique der 2. Sitzung des Kontrollrats vom 10. August 1945 (Auszug) .

B. Kommuniqué der 3. Sitzung des Kontroll rats vom 20. August 1945 (Auszug) .

C. Kommuniqué der 4. Sitzung der Kontrollrats vom 30. August 1945 (Auszug) .

D. Kommuniqué des Koordinierungskomitees vom 26. Oktober 1945 (Auszug) .

E. Kommuniqué der 12. Sitzung des Kontrollrats vom 20. November 1945 (Auszug)

F. Kommuniqué der 27. Sitzung des Koordinierungskomitecs vom 17. Dezember 1945 (Auszug) . . . . . . . . . . . . . . . .

G. Kommuniqué der 36. Sitzung des Koordinierungskomitees vom 7. Februar 1946 (Auszug) . . . . . . . . . . . . . . . . .

32. Bericht des Transportdirektorats über die Berliner Kohlen- und Nahrungmittelrersorgung, vom Kontrollrat bestätigt auf seiner Sitzung am 10. September 1945 (CONL/P [45] 27) .

33. Bericht des Luffahrtsdirektorats über die Sdhaffung eines Systems von Luftkorridoren, vom Koordinierungskomitee am 27. November 1945 gebilligt und vom Kontrollrat am 30. November 1945 bestätigt (CONL/P [45] 63) . . . . . . .

34. Protokoll (CONL/M [45] 13) der 13. Sitzung des Alliierten Kontrollrats vom 30. November 1945 (Auszug) . . . . . . . . . . . . 45

35. Memorandum des amerikanischen Mitglieds des Koordinierungskomitees (CORC/P [46] 84) vom 6. März 1946 betr. die Errichtung zusätzlicher Luftkorridore . . .

36. Stellungnahme der sowjetischen Delegation in der 29. Sitzung des Luftfahrtdirektorats vom 30. April 1946 zur Frage zusätzlicher Lufkorridore (Auszug aus dem Protokoll DAIR/M [46] 11) . . . . . . . . . . . . .

37. Flugvorschriften für Flugzeuge, die die Luftkorridore in Deutschland und die Kontrollzone Berlin befliegen (DAIR/P [45] 71), in der vom Luftfahrtdirektorat rerabschiedeten 2. abgeänderten Fassung vom 22. Oktober 1946 . . . . 
38. Sowjetischer Beridut vom 5. Februar 1947 zur Entwidklung der Frage „Flüge alliierter Flugzcuge über deutschem Gebiet" (Auszug aus Anhang E zu DOCS/SEC [47] 33) ..................

\section{KAPITEL VIII}

Das Ausschciden der Sowjetunion aus dem Alliierten Kontrollrat für Deutschland und der Alliicrten Kommandantur der Stadt Berlin

39. Befehl Nr. 32/1948 der Sowjetischen Militïrverwaltung in Deutschland (SMA) vom 12. Februar 1948 über Zusanmensetzung und Vollmactien der Deutschen Wirtschafts-Kommission

40. Note der Sowjetunion an die Vercinigten Staaten, Großbritannien und Frankreich voln 13. Februar 1948 über die Londoner Deutschland-Besprechungen . . . . .

41. Note der Vereinigten Staaten an die Sowjetunion vom 21. Februar 1948 über die Londuner Deutschland-Besprechungen ..............

42. Note der Sowjetunion an die Vercinigten Staaten, Großbritannien und Frankreich vom 6. März 1948 über die Londoner Deutschland-Besprechungen (Auszug) . . .

43. Erklïrung des sowjetischen Vertreters im Alliierten Kontrollrat, Marschall Sokolowski, am 20. Mïrz 1948 (Auszug) . . . . . . . . . . . . . . .

44. Note der Vereinigten Staaten an die Sowjetunion vom 26. März 1948 über die Londoner Deutsdul:and-Besprechungen (Auszug)

45. Bericht über das Sthreiben des stellvertretenden sowjetischen Militärgouverneurs, General Dratwin, vom 30. Mïrz 1948 an die Militärregierungen der drei Westmädte über neue Bestimmungen über den Verkehr zwischen den Besatzungszonen ........................

46. Antwort des Chefs des Stabes der amerikanischen Militärregierung, General Gailey, vom 31. März 1948 auf das Schreiben General Dratwins (Auszug) . . .

47. Beschluß der Stadtverordnetenversammlung von Groß-Berlin vom 13. Juni 1948 zu den "Londoner Empfehlungen" vom 7. Juli 1948 . . . . . . . . . .

4S. Sowjetische Verlautbarung vom 1. Juli 1948 über die Einstellung der Mitarbeit der Sowjetunion an der Arbeit der Alliierten Kommandantur der Stadt Berlin seit dem 16. Juni 1948

\section{KAPITEL IX}

\section{Die Währungsreform in Berlin und der Beginn der Berliner Blockade}

49. Schreiben des britischen Militïrgouverneurs an den sowjetischen Militärgouverneur vom 18. Juni 1948 über die Einführung der Währungsreform in den westlichen Besatzungszonen Deutschlands . . . . . . . . . . .

50. Mitteilung der Sowjetischen Militärverwaltung in Deutschland (SMA) vom 18. Juni 1948 über die Unterbrechung des Interzonenverkehrs . . . . . . . . .

51. Aufruf der Sowjetischen Militärverwaltung in Deutschland (SMA) vom 19. Juni 1948 an die deutshe Berölkerung (Auszug) . . . . . . . . . . . .

52. Schreiben des sow jetischen Militïrgourerneurs an General Clay vom 22. Juni 1948 über die Einführung der Währungsreform in der sowjetischen Besatzungszone und in Groß-Berlin

53. Schreiben des Chefs des Stabes der Sowjetischen Mlilitärverwaltung in Deutschland (SMA) vom 22. Juni 1948 an den amtierenden Oberbürgermeister von Groß-Berlin

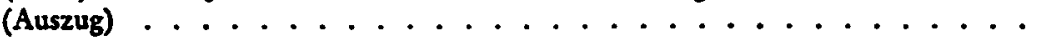


54. Shreiben des britischen Militärgouverneurs an den sowjetischen Militärgouverneur vom 23. Juni 1948 über die Währungsreform in Groß-Berlin . . . . . . . . 70

55. Befehl der Kommandanten der Westscktoren von Groß-Berlin vom 23. Juni 1948 (Auszug) ....................... 71

56. ADN-Meldung vom 24. Juni 1948 über die Unterbrechung der Eisenbahnstrecke Berlin-Helmstedt

\section{KAPITEL $\mathbf{X}$}

Die ergebnislosen Bemühungen um die Aufbebung der Berliner Blockade

57. Appell der städtischen Körperschaften von Groß-Berlin an die Vercinten Nationen vom 29. Juni $1948 \ldots \ldots \ldots$

58. Note der Vercinigten Staaten an die Sowjetunion vom 6. Juli 1948 über die Lage in Berlin ..........................

59. Note der Sowjetunion an die Vercinigten Staaten, Großbritannien und Frankreich vom 14. Juli 1948 über die Lage in Berlin . . . . . . . . . . . . . 77

60. Direktive der Regierungen der Sowjetunion, der Vereinigten Staaten, Großbritanniens und Frankreichs vom 30 . August 1948 an die vier Militärgouverncure in Berlin . . . . . . . . . . . . . . . . . . . .

61. Gemeinsamer Bericht der britischen, amerikanischen und französischen Militärgouverneure in Deutschland vom 7. September 1948 über die Berliner Besprechungen der vier Militärgouverneure . . . . . . . . . . . .

\section{KAPITEL XI}

Die Teilnabme Berlins an den Arbeiten des Parlamentarischen Rates in Bonn

62. Beschluß des Parlamentarischen Rates vom 1. September 1948 über dic Teilnahme der Vertreter Berlins an den Arbeiten des Parlamentarischen Rates (Auszug) . .

63. Beschluß der Stadtverordnetenversammlung von Groß-Berlin vom 27. September 1948 über die Beteiligung am Parlamentarischen Rat . . . . . . . . . 8

\section{KAPITEL XII}

\section{Die Berliner Frage vor den Vereinten Nationen}

64. Note der Vereinigten Staaten, Großbritanniens und Frankreichs an die Sowjetunion rom 22. September 1948 über die Berliner Blockade . . . . . . . . .

65. Note der Sowjetunion vom 25. September 1948 an die Vereinigten Stazten, Großbritannien und Frankreich zur Berliner Frage . . . . . . . . 86

66. Kommuniqué der Außenministerbesprechungen der drei Westmächte in Paris vom 26. September 1948 zur Berliner Lage . . . . . . . . . . . . . . . 89

67. Note der drei Westmähte an die Sowjetunion rom 27. September 1948 über die Anrufung des Sicherheitsrats in der Berliner Frage . . . . . . . . .

68. Gemeinsame Mitreilung des Präsidenten der Vollversammlung und des Generalsekretärs der Vereinten Nationen vom 13. November 1948 an die Vorsitzenden der amerikanischen, britischen und sowjetischen Delegation zur Berlin-Frage . . 96 


\section{KAPITEL XIII}

Der kommunistisdbe Staatsstreich im sowjetischen Scktor von Groß-Berlin und die Berliner Wablen vom S. Dezember 1948

69. Protest der Mehrhcitsparteien der Stadtverordnetenversammlung von GroßBerlin vom 8. September 1948 gegen die Behinderung der parlamentarischen Arbeit im sowjetischen Sektor (Auszug) . . . . . . . . . . . . . .

70. Sdireiben des sowjetischen Kommandanten von Berlin vom 20. Oktober 1948 an den Magistrat von Groß-Berlin über die Abhaltung der Berliner Wahlen . . . .

71. Aufruf der Stadtverordnetenversammlung von Groß-Berlin vom 26. November 1948 an die Bevölkerung Berlins zur Wahl am 5. Dezember 1948 . . . . . .

72. Befchl Nr. 183/1948 des Obersten Chefs der Sowjetischen Militz̈rverwaltung in Deutschland (SMA) vom 27. November 1948 über die Erweiterung der Deutschen Wirtschaftskommission (Auszug) . . . . . . . . . . . . 100

73. Schreiben des Obersten Chefs der Sowjetischen Militärverwaltung in Deutschland (SMA) rom 29. November 1948 an den Oberbefchlshaber der britischen Besatzungstruppen über die Wahlen in Berlin . . . . . . . . . . . . . . 101

74. Resolution der sog. Außerordentlichen Stadtverordnetenversammlung rom 30. November 1948 im Ost-Berliner Admiralspalast über die Absetzung des Magistrats von Groß-Berlin . . . . . . . . . . . . . . . . . 102

75. Gemeinsamer Protest der Militz̈rgouverneure der drei Westmächte an den Chef der Sowjetischen Militïrverwaltung (SMA) vom 30. November 1948 gegen die Entwidklung in Berlin ................. 102

76. Beschluß der Stadtverordnetenversammlung von Groß-Berlin vom 1. Dezember 1948 über den kommunistischen Stantsstreich im sowjetischen Sektor Berlins . . . 103

77. Schrciben des sowjetischen Militärkommandanten von Berlin vom 2. Dezember 1948 an den Vorsitzenden der Außerordentlichen Sitzung der Stadt- und Bezirksverordnetenversammlung im Ost-Berliner Admiralspalast . . . . . . . . . 104

78. Erklärung der Kommandanten der Westsektoren von Groß-Berlin vom 21. Dezember 1948 über die Fortführung der Tätigkeit der Alliierten Kommandantur der Stadt Berlin . . . . . . . . . . . . . . . . 105

79. Erklärung der Militärgouverneure der drei Westmächte vom 20. März 1949 über die Einführung der D-Mark West als alleiniges Zahlungsmittel in den Westsektoren von Groß-Berlin . . . . . . . . . . . . . . 106

\section{KAPITEL XIV}

\section{Die Aufbebung der Berliner Blockade}

80. Erklärung des amerikanischen Außenministeriums rom 26. April 1949 zur Berliner Frage . . . . . . . . . . . . . . . . . 107

81. New Yorker Abkommen der Vereinigten Staaten, Großbritanniens, Frankreichs und der Sowjetunion vom 4. Mai 1949 über die Aufhebung der Berliner Blodkade 108 A. Erklärung der Vertreter der drei Westmächte im Sicherheitsrat vom 4. Mai 1949 an den Generalsekretïr der Vereinten Nationen . . . . . . . . . . 108 B. Viermähtekommuniqué vom 4. Mai 1949 . . . . . . . . . . . . . . . 109

S2. Befehl Nr. 56 des Obersten Chefs der Sowjetischen Militärverwaltung in Deutschland (SMA) rom 9. Mai 1949 über die Aufhebung der Berliner Blodsade . . . . 109 


\section{KAPITEL XV}

\section{Die Einbeziebung Berlins in den Entwurf des Grundgesetzes der Bundesrepublik Deutschland}

83. Erklärung des Informationsbüros der Sowjetischen Militärverwaltung in Deutschland (SMA) vom 10. Februar 1949 zur Einbezichung Berlins in den Entwurf des Grundgesetzes für die Bundesrepublik Deutschland . . . . . . . . . . 112

84. Memorandum der Militärgouverncure der drei Westmächte vom 2. März 1949 zum Entwurf des Grundgesetzes der Bundesrepublik Deutschland (Auszug) . . . 112

85. Schreiben der Militärgouverneure der drci Westmächte vom 22. April 1949 über die Auffassungen der Außenminister ihrer Länder zum Entwurf des Grundgesetzes der Bundesrepublik Deutschland (Auszug) . . . . . . . . . . 113

86. Beschlüsse der Stadtverordnetenversammlung von Groß-Berlin vom 19. Mai 1949 zum Grundgesetz der Bundesrepublik Deutschland . . . . . . . . . . . 113 A. Annahme des Grundgesetzes . . . . . . . . . . . . . . . 113

B. Bekenntnis zu den Prinzipien und Zielen des Grundgesezzes . . . . . . . 113

\section{KAPITEL XVI}

\section{Das Besatzungsstatut für West-Berlin vom 14. Mai 1949}

87. Schreiben der Alliierten Kommandantur der Stadt Berlin vom 14. Mai 1949 über die Grundsätze der Beziehungen der Stadt Groß-Berlin zur Alliierten Kommandantur . . . . . . . . . . . . . . . . . . . . . 114

A. Schreiben der Kommandanten der Westsektoren an den Stadtverordnetenvorsteher, den Oberbürgermeister und den Präsidenten des Kammergeriates vom 14. Mai 1949 . . . . . . . . . . . . . . . . . . . . . . 114

B. Erklärung über die Grundsätze der Beziehungen der Stadt Groß-Berlin zu der Alliierten Kommandantur . . . . . . . . . . . . . . 115

C. Erläuterungen zu Paragraph 2 (1) der Erklärung über die Grundsätze der Beziehungen der Stadt Groß-Berlin zu der Alliierten Kommandantur vom 14. Mai 1949 . . . . . . . . . . . . . . . . . . . . 118

88. Abkommen über die revidierte Geschäftsordnung der Alliierten Kommandantur der Stadt Berlin vom 7. Juni 1949 auf Grund des Washingtoner Abkommens der drei Westmächte über die Dreimächtekontrolle Deutshlands vom 8. April 1949 .

\section{KAPITEL XVII}

\section{Die Pariser Außenministerkonferenz und das Sheitern der Viererverbandlungen} in Berlin

89. Kommuniqué vom 20. Juni 1949 über die Sechste Tagung des Rates der Außenminister in Paris (Auszug) . . . . . . . . . . . . 120

90. Beschlüsse der Stadtverordnetenversammlung von Groß-Berlin vom 21. Juni 1949 über die Eingliederung Berlins in die Bundesrepublik . . . . . . . . . . 122 A. Ober die Einbeziehung Berlins als Land in die Bundesrepublik . . . . . . 122 B. Ober die Wahl der Berliner Bundestagsabgeordneten . . . . . . . . . 122

91. Anordnung der Alliierten Kommandantur der Stadt Berlin vom 30. Juni 1949 zu den Beschlüssen der Stadtverordnetenversammlung vom 21. Juni 1949 . . . . . 122

92. Bericht des amerikanischen Hohen Kommissars in Deutschland ïber den Abbruch der Arbeiten der Alliierten Kommandantur der Stadt Berlin am 28. September 1949 (Auszug) . . . . . . . . . . . . . . . 123 


\section{KAPITEL XVIII}

\section{Berlin und das Grundgesetz der Bundesrepublik Deutschland}

\section{Abschnitt: Berlin im Grundgesetz}

93. Das Grundgesctz für die Bundesrepublik Deutschland vom 23. Mai 1949 (Auszug) 123

94. Shreiben der Militärgouverneure der drei Westmächte vom 12. Mai 1949 an den Präsidenten des Parlamentarischen Rates (Auszug) . . . . . . . . . . 124

\section{Absdonitt: Die Geltung des Grundgesetzes für Berlin}

95. Beschluß des Bundesverfassungsgerichts vom 25. Oktober 1951 über die Geltung des Grundrechtsteils für Berlin (Auszug) . . . . . . . . . . . . . . . 125

96. Sdhreiben der Alliierten Hohen Kommission an den Bundeskanzler vom 16. Oktober 1952 über die Erwähnung Berlins in Bundesgesetzen (AGSEC [52] 1029) . . 126

97. Einspruch der Alliierten Kommandantur der Stadt Berlin vom 20. Dezember 1952 gegen cine Ubernahme des Bundesverfassungsgerichtsgesetzes (BK/O [52] 35) . . 127

98. Senatsbeschluß vom 14. Mai 1956 über die Vereidigung von Berliner Beamten auf das Grundgesetz . . . . . . . . . . . . . . . . . . . . . 127

A. Senatsbeschluß vom 14. Mai $1956 \ldots \ldots 127$

B. Genchmigung der Alliierten Kommandantur der Stadt Berlin (BK/L [56] 21) 128

99. Beschluß des Bundesverfassungsgeridhts vom 21. Mai 1957 (2 Bvl 6/56) über die Geltung des Grundgesetzes für Berlin (Auszug) . . . . . . . . . . 128

\section{Abschnitt: Die Vertretung Berlins im Deutschen Bundestag}

100. Wahlgesetz zum ersten Bundestag und zur Bundesversammlung vom 15. Juni 1949 (Auszug) ....................... 133

101. Schreiben der Alliierten Hohen Kommission vom 24. Juni 1953 an den Bundeskanzler zum Entwurf des Bundeswahlgesetzes (AGSEC [53] 550) . . . . . . 134

102. Wahlgesetz zum zweiten Bundestag und zur Bundesversammlung vom 8. Juli 1953 (Auszug) . . . . . . . . . . . . . . . . . . 135

103. Berliner Gesetz vom 7. Juli 1953 über die Wahl der Vertreter des Landes Berlin zum zweiten Bundestag (Auszug) . . . . . . . . . . . . 136

104. Schreiben des Botschafters der Vereinigten Staaten an den Bundeskanzler vom 10. März 1956 über die Stellung der Berliner Vertreter im Bundestag . . . . . . 135

105. Bundeswahlgesetz vom 7. Mai 1956 (Auszug) . . . . . . . . . . . . 137

\section{KAPITEL XIX}

Die Gründung der Deutschen Demokratischen Republik (DDR)

106. Note der Sowjetunion an die Vereinigten Staaten, Großbritannien und Frankreich vom 1. Oktober 1949 über die Lage in Deutschland (Auszug) . . . . . 138

107. Verfassung der Deutschen Demokratischen Republik (DDR) vom 7. Oktober 1949 (Auszug) . . . . . . . . . . . . . . . . . 139

108. Gesetz über die Bildung einer Provisorischen Länderkammer der DDR vom 7. Oktober 1949 (Auszug) . . . . . . . . . . . . . . 139

109. Erklärung des Vorsitzenden der Sowjetischen Kontrollkommission für Deutschland, Tschuikow, 2m 11. November $19+9$ über die Bildung der Sowjetischen Kontrollkommission und die Ubertragung der Verwaltungsfunktionen der Sowjetischen Militärverwaltung in Deutschland (SMA) an die Organe der DDR . . . . 1to

A. Erklärung Tschuikows . . . . . . . . . . . . . . . 140

B. Antwortrede des Ministerpräsidenten Otto Grotewohl (Auszug) . . . . . . 1+2 
C. Antwortrede des Oberbürgermeisters von Groß-Berlin (Ost), Ebert, bei der Ubergabe der Verwaltungsfunktionen der sowjetischen Militärkommandantur an den Berliner Magistrat durch den Stadtkommandanten, Generalmajor Kotikow, am 12. November 1949 (Auszug) . . . . . . . . . . . . . . .

\section{KAPITEL XX}

Proteste der Westmäcbte und der Bundesrepublik Deutschland gegen die Gründung der $D D R$ und Erklärungen über Hilfsmaßnabmen für West-Berlin

110. Erklärung des amerikanischen Außenministers Acheson vom 12. Oktober 1949 über die Gründung der DDR (Auszug) . . . . . . . . . . . . . . . 143

111. Erklärung der Bundesregierung vor dem Deutschen Bundestag vom 21. Oktober 1949 zur Bildung der DDR und zur Lage Berlins (Auszug) . . . . . . . . 144

112. Erklärung der Alliierten Hohen Kommission in Deutschland vom 21. Oktober 1949 über Berlin . . . . . . . . . . . . . . . . . . . 145

113. Vertrag über wirtschaftliche Zusammenarbeit zwischen der Bundesrepublik Deutschland und den Vereinigten Staaten von Amerika vom 15. Dezember 1949 (Auszug) . . . . . . . . . . . . . . . 146

\section{KAPITEL XXI}

\section{Die Bemühungen um freie Wablen in Gesamt-Berlin}

114. Beschluß der Stadtverordnetenversammlung von Groß-Berlin vom 20. April 1950 über die Abhaltung freier Wahlen in ganz Berlin . . . . . . . . . 146

115. Schreiben des britischen Stadtkommandanten von Berlin an den Oberbürgermeister von Berlin vom 21. April 1950 über die Abhaltung freier Wahlen in ganz Berlin . 147

116. Schreiben des Vertreters der Sowjetischen Kontrollkommission, Jelisarow, an die Kommandanten der drei Westsektoren Berlins vom 8. Mai 1950 über freie Wahlen in ganz Berlin . . . . . . . . . . . . . . . . 147

117. Londoner Erklärung der Außenminister der drei Westmähtıe rom 12. Mai 1950 über Berlin . . . . . . . . . . . . . . . . . . . 148

118. Beschluß der Stadtverordnetenversammlung von Groß-Berlin vom 1. Juni 1950 über freie Wahlen in ganz Berlin . . . . . . . . . . . . . . 149

119. Schreiben der Kommandanten der drei Westsektoren an den Vertreter der Sowjetischen Kontrollkommission vom 9. Juni 1950 über freie Wahlen in ganz Berlin . . 150

120. Schreiben des Vertreters der Sowjetischen Kontrollkommission, Dengine, an die Kommandanten der drei Westsektoren vom 24. Juni 1950 über Wahlen in ganz Berlin

\section{KAPITEL XXII}

Die Berliner Verfassung von 1950

121. Erklärung der Kommandanten der drei Westsektoren von Groß-Berlin vom 29. August 1950 zur Verfassung Berlins . . . . . . . . . . . . . 153

A. Die Erklärung . . . . . . . . . . . . . . . 153

B. Schreiben der Alliierten Kommandantur der Stadt Berlin vom 29. August 1950 über Zustimmung und Vorbehalte zur Berliner Verfassung (BK/O [50] 75) . 154

122. Verfassung von Berlin vom 1. September 1950 (Auszug) . . . . . . . . 154 
123. Beschluß der Stadtverordnetenversammlung von Groß-Berlin vom 29. September 1950 über die Abhaltung von Wahlen in Berlin am 3. Dezember 1950 . . . . 157

124. Gesetz vom 27. März 1951 über eine Vertretung der an der Wahl verhinderten Kreise (des sowjetischen Sektors) im Abgeordnetenhaus von Berlin (Auszug) . . 157

125. Regicrungserklärung des Regierenden Bürgermeisters von Berlin vom 1. Februar 1951 über die Legitimität des Senats von Berlin . . . . . . . . . . . . . . 157

126. Gesetz über die Wahlen zum Abgeordnetenhaus und zu den Bezirksverordnctenversammlungen (Landeswahlgesetz) vom 28. März 1958 (Auszug) . . . . . . . 158

\section{KAPITEL XXIII}

Die Beziebungen der Berliner Bebörden zur Alliierten Kommandantur der Stadt Bcrlin

127. Grundsatzerklärung über die Befugnisse und Beziehungen des amerikanischen Stadtkommandanten von Berlin vom 5. August 1950 (Auszug) . . . . . . . 158

128. New Yorker Kommuniqué der Außenminister der drei Westmächte über Deutschland rom 19. September 1950 (Auszug) . . . . . . . . . . . . . . 160

129. Schreiben der Alliierten Kommandantur der Stadt Berlin vom 7. März 1951 über die Revision des Berliner Besatzungsstatuts vom 14. Mai 1949 . . . . . . . . 161

A. Schreiben vom 7. März 1951 (BK/L [51] 29) . . . . . . . . . . . . . 161

B. Erste Abänderungsurkunde zur Erklärung über die Grundsätze vom 14. Mai 1949 .................... . . 162

130. Erklärung der Alliierten Kommandantur der Stadt Berlin vom 26. Mai 1952 anläßlich der Neuordnung der Beziehungen 2wischen den drei Westmächten und der Bundesrepublik . . . . . . . . . . . . . . . . . . . 164

A. Schreiben vom 26. Mai 1952 (BKC/L [52] 7) . . . . . . . . . . . . . 164

B. Erklärung . . . . . . . . . . . . . . . 164

\section{KAPITEL XXIV}

\section{Die Gestaltung der Bezichungen West-Berlins zur Bundesrepublik Deutschland}

1. Abschnitt: Die Ubernahme von Bundesrecht durch West-Berlin

131. Sdhreiben der Alliierten Kommandantur der Stadt Berlin vom 8. Oktober 1951 über die Möglichkeit der Mantelgesetzgebung (BK'O [51] 56 in der Fassung der BK/O [55] 10 vom 14. Mai 1955) ............. . . 166

132. Schreiben der Alliierten Kommandantur der Stadt Berlin vom 13. November 1951 über die Befugnisse der Besatzungsbehörden (BK/O [51] 63) . . . . . . . . . 167

133. Schreiben der Alliierten Kommandantur der Stadt Berlin vom 23. Februar 1952 über die Möglichkeit eines Mantelgesetzes (BK/L [52] 19) . . . . . . . . 167

134. Schreiben der Alliierten Kommandantur der Stadt Berlin vom 28. August 1952 über die Form eines Mantelgesetzes (BK/L [52] 81) . . . . . . . . . . . . 168

135. Muster eines Mantelgesetzes . . . . . . . . . . . . . . . . . . . . . . . 169

136. Kabinettsbeschluß der Bundesregierung über die Fassung der Vorschriften zur Erstreckung von Bundesrecht auf Berlin (Berlinklausel) . . . . . . . 169

2. Abschnitt: Die Einbeziebung West-Berlins in die internationalen Verträge der Bundesrepublik

137. Sdireiben des Regierenden Bürgermeisters von Berlin an den Bundeskanzler rom 9. April 1951 über die Einbeziehung Berlins in die internationalen Verträge der Bundesrepublik . . . . . . . . . . . . . . . 174

\section{XVIII}


138. Erklärung der Alliierten Kommandantur der Stadt Berlin vom 21. Mai 1952 über die Einbezichung Berlins in internationale Verträge und Verpflichtungen der Bundesrepublik . . . . . . . . . . . . . . . . . 175

A. Schreiben vom 21. Mai 1952 (BKC/L [52] 6) . . . . . . . . . . . . 175

B. Erklärung . . . . . . . . . . . . . . . 175

139. Das Verhältnis West-Berlins zur Montanunion . . . . . . . . . . . . . . 177

A. Erklärung des Bundeskanzlers vom 9. Januar 1952 im Bundestag (Auszug) . 177

B. Mittcilung Nr. 212 des Berliner Senats vom 20. Oktober 1952 über die Ratifizicrung des Schuman-Planes . . . . . . . . . . . . . . 178

140. Vereinbarung zwischen dem Senat von Berlin und der Bundesregierung vom 19. Dezember 1952 über die Einbeziehung Berlins in internationale Verträge und Verpflichtungen der Bundesrepublik . . . . . . . . . . . . . . . . 179

A. Schrciben des Regierenden Bürgermeisters vom 16. September 1952 . . . . . 179

B. Schreiben des Bundeskanzlers vom 19. Dezember 1952 . . . . . . . . . . 180

C. Vorlage Nr. 122 des Berliner Senats über den Stand der Verhandlungen . . . 181

141. Gesetz über die Verkündung von Gesetzen und Rechtsverordnungen vom 29. Januar 1953 (Auszug) . . . . . . . . . . . . . . 181

142. Die Einbeziehung Berlins in die Europäische Wirtschaftsgemeinschaft und die Europäische Atomgemeinschaft . . . . . . . . . . . . . 182

A. Schlußakte der Regierungskonferenz vom 25. März 1957 über die Europäische Wirtschaftsgemeinschaft und die Europäische Atomgemeinschaft (Auszug) . 182

B. Protokoll über den innerdeutschen Handel . . . . . . . . . . 182

C. Erklärung der Bundesregierung vom 9. Dezember 1957 bei der Hinterlegung der deutschen Ratifizierungsurkunde zu den Verträgen vom 25. März 1957 . 183

D. Schreiben der Alliierten Kommandantur der Stadt Berlin vom 18. November 1957 zur Einbeziehung Berlins in die Verträge (BK/L [57] 44) . . . . . 183

143. Note der Ständigen Delegation der Sowjetunion bei den Vereinten Nationen vom 6. Januar 1958 an den Generalsekretär über Berlin als Hauptstadt der DDR 184

144. Notenwechsel $z$ wischen der Botschaft der Sowjetunion in Washington und dem amerikanischen Außenministerium vom 11. und 20. August 1958 über die BerlinErklärung der Bundesrepublik bei Ratifzierung der Satzung der Internationalen Atomenergie-Organisation . . . . . . . . . . . . . . . . . 184

A. Note der Sowjetbotschaft vom 11. August 1958 . . . . . . . . . . . 184

B. Note des amerikanischen Außenministeriums vom 20. August $1958 \ldots 185$

\section{Abschnitt: Das Dritte Uberleitungsgesetz}

145. Gesetz über die Stellung des Landes Berlin im Finanzsystem des Bundes (Drittes Uberleitungsgesetz) vom 4. Januar 1952 . . . . . . . . . . . . . 186

146. Schreiben der Alliierten Hohen Kommission an den Bundeskanzler vom 17. Januar 1952 über die Aufhebung gewisser Vorschriften des 3. Oberleitungsgesetzes (AGSEC [52] 52) . . . . . . . . . . . . . . . . . . . . 192

147. Presseverlautbarung Nr. 396 der Alliierten Hohen Komission für Deutschland vom 18. Januar 1952 über den Status Berlins außerhalb des Bundes. . . . . . 193

\section{Abschnitt: Die Vertretung Berlins bei der Bundesrepublik und die Vertretung} der Bundesrepublik in Berlin

148. Bekanntmachung des Oberbürgermeisters von Berlin vom 25. Juni 1949 über die Vertretung des Magistrats bei der Bundesrepublik Deutschland . . . . . . . . 194

149. Erlaß der Bundesregierung vom 30. November 1953 über die Aufgaben und Befugnisse des Bevollmächtigten der Bundesrepublik Deutschland in Berlin . . . 195 


\section{KAPITEL XXV}

Die Angleichung Ost-Berlins an die Herrschaftsstruktur der DDR in den Jabren 1950-1954

150. Geschäftsordnung des Magistrats von Groß-Berlin (Ost) vom 29. März 1950 (Auszug) ...................... . 196

151. Hauptsatzung für die Verwaltung von Groß-Berlin (Ost) vom 8. Juni 1950 (Auszug) . . . . . . . . . . . . . . . . . . . . . . . 197

152. Gesetz über die Wahlen zur Volkskammer, zu den Landtagen, Kreistagen und Gemeindevertretungen in der Deutschen Demokratischen Republik vom 9. August 1950 (Auszug) . . . . . . . . . . . . . . . . . . . . . . . . 199

153. Gesetz über die Zusammensetzung der Länderkammer der Deutschen Demokratischen Republik rom 8. November 1950 (Auszug) . . . . . . . . . . . . . 199

154. Verordnung des Magistrats von Groß-Berlin (Ost) über die weitere Demokratisierung des Aufbaus und der Arbeitsweise der Organe der Staatsmacti von GroßBerlin (Ost) rom 19. Januar 1953 . . . . . . . . . . . . . . . . . . . . 199

155. Vorläufige Ordnung für den Aufbau und die Arbeitsweise der Organe der Staatsmacht von Groß-Berlin (Ost) vom 23. Januar 1953 (Auszug) . . . . . . . . . 201

156. Direktive für die staatspolitische Schulung und die fachliche Weiterbildung der Mitarbeiter in den Organen der Staatsmacht von Groß-Berlin (Ost) vom 27. Februar 1953 (Auszug) . . . . . . . . . . . . . . . . . . 203

157. Verordnung des Magistrats von Groß-Berlin (Ost) vom 11. November 1953 über die Ausgabe von Personalausweisen der DDR in Groß-Berlin (Ost) (Auszug) . . 205

158. Bekanntmachung des Beschlusses des Magistrats von Groß-Berlin (Ost) zur Verbesserung der Kontrolle der Durchführung der Gesetze, Verordnungen und Beschlüsse durch die Organe der Staatsmacht von Groß-Berlin (Ost) vom 5. Februar 1954 (Auszug) . . . . . . . . . . . . . . . . . 205

159. Verordnung der Volksvertretung Groß-Berlin (Ost) vom 15. März 1954 zum Volkswirtschaftsplan 1954 (Auszug) . . . . . . . . . . . 206

160. Verordnung des Magistrats von Groß-Berlin (Ost) über den Haushaltsplan von Groß-Berlin für 1954 vom 22. März 1954 (Auszug) . . . . . . . . . . . . . 207

\section{KAPITEL XXVI}

Die Gewährung der Souveränität an die $D D R$ und die weitere Angleidhung Ost-Berlins an die Herrschaftsstruktur der DDR 1954-1955

161. Erklärung der Sowjetregierung vom 25. März 1954 über die Gewährung der Souveränität an die Deutsche Demokratische Republik (Auszug) . . . . . . . 2 C8

162. Erklärung des Ministerrats der DDR vom 27. März 1954 über die Herstellung der Souveränität (Auszug) . . . . . . . . . . . . . . . . . . . 209

163. Erklärung der Hohen Kommissare der drei Westmächte vom 8. April 1954 über die Nichtanerkennung der Souveränität der DDR . . . . . . . . . . . . . 209

164. Bekanntmachung des Beschlusses des Magistrats von Groß-Berlin (Ost) über die Volksbefragung für einen Friedensvertrag ... vom 31. Mai 1954 (Auszug) . . . 210

165. Beschluß der Regierung der Sowjetunion vom 7. August 1954 über die Aufhebung von Besatzungsbefehlen ................... 211

166. Gesetz über die Wahlen zur Volkskammer der DDR am 17. Oktober 1954 rom 4. August 1954 (Auszug) . . . . . . . . . . . . . . . . . . . . 212 
167. Verordnung der Volksvertretung Groß-Berlin (Ost) vom 13. August 1954 über dic Wahlen zur Volksvertretung von Groß-Berlin (Ost) am 17. Oktober 1954 (Auszug) ........................ . . 212

168. Verordnung des Magistrats von Groß-Berlin (Ost) über den Verkehr mit ausländischen Dienststellen vom 15. Dezember 1954 (Auszug) . . . . . . . . . . 213

169. Arbeitsordnung des Magistrats von Groß-Berlin (Ost) vom 17. Mai 1955 (Auszug) 215

\section{KAPITEL XXVII}

Berlin und die Neuordnung der Bezichungen der Bundesrepublik zur westlichen Welt in den Pariser Verträgen und im Beitritt der Bundesrepublik zur WEU und NATO

\section{Abschnitt: Die Pariser Verträge}

170. Erklärung der Vereinigten Staaten von Amerika, Großbritanniens und Frankreichs auf der Londoner Neunmächtekonferenz vom 28. September bis zum 3. Oktober 1954 (Auszug) . . . . . . . . . . . . . . . . . . . . . . 216

171. Vertrag über die Beziehungen zwischen der Bundesrepublik Deutschland und den Drei Mäctiten vom 26. Mai 1952 in der durch das Protokoll vom 23. Oktober 1954 abgeänderten Fassung (Auszug) . . . . . . . . . . . . . . 217

172. Begründung der Bundesregierung zum Gesetz über den Vertrag vom 23. Oktober 1954 über die Beziehungen zwischen der Bundesrepublik und den Drei Mächten

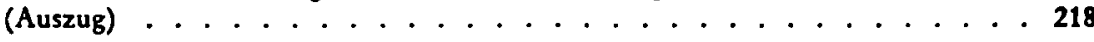

173. Finanzvertrag zwischen der Bundesrepublik und den Drei Mächten in der durch das Protokoll vom 23. Oktober 1954 abgeänderten Fassung. (Auszug) . . . . . 219

174. Vertrag über die Rechte und Pflichten ausländischer Streitkräfte und ihrer Mitglieder in der Bundesrepublik Deutschland in der Fassung vom 23. Oktober 1954 (Auszug) . . . . . . . . . . . . . . . . . . 220

175. Vertrag zur Regelung aus Krieg und Besatzung entstandener Fragen zwischen der Bundesrepublik und den Drei Mächten in der durch das Protokoll vom 23. Oktober 1954 abgeänderten Fassung (Auszug) . . . . . . . . . . . . . . 220

176. Schreiben der drei Hohen Kommissare an den Bundeskanzler vom 26. Mai 1952 über die Ausübung des den Drei Mäctten vorbehaltenen Rechtes in bezug auf Deutschland als Ganzes in der Fassung des Schreibens Nr. X vom 23. Oktober 1954221

177. Schreiben der drei Hohen Kommissare an den Bundeskanzler vom 26. Mai 1952 über die Ausübung des den Drei Mächten vorbehaltenen Rechtes in bezug auf Berlin in der Fassung des Schreibens Nr. X vom 23. Oktober 1954 . . . . . . . 221

178. Erklärung der Bundesregierung über Hilfeleistung für Berlin vom 23. Oktober 1954223

179. Schreiben Nr. 8a der drei Außenminister an den Bundeskanzler vom 26. Mai 1952 über die Aufrechterhaltung gewrisser Kontrollratsvorschriften . . . . . . . 224

180. Schreiben des Bundeskanzlers an die drei Außenminister vom 26. Mai 1952 über über Bestätigung des Schreibens Nr.8a . . . . . . . . . . . 224

181. Schreiben Nr. IXa der drei Hohen Kommissare an den Bundeskanzler vom 23. Oktober 1954 über den Luftverkehr nach und von den Berliner Luftschneisen 225

182. Abkommen der drei Westmächte über die Ausübung der vorbehaltenen Rechte in Deutschland vom 23. Oktober $1954 \ldots . . . . . . . . .225$ 


\section{Abscbnitt: Berlin und die Mitgliedsdsaft der Bundesrepublik im Nordatlantikpakt}

183. Entschlicßung des Nordatlantikrates vom 22. Oktober 1954 über die Zustimmungscrklärung der übrigen Partcien des Nordatlantikvertrags zu den auf der Londoner Konferenz abgegebenen Erklärungen der Bundesrepublik und der Drei Mähte . . . . . . . . . . . . . . . . . . . 226

184. Nordatlantikvertrag vom 4. April 1949 (Auszug) . . . . . . . . . . . . 227

185. Kommuniqué der Tagung des Nordatlantikrates vom 16. Dezember 1955 (Auszug) 227

186. Kommuniqué der Tagung des Nordatlantikrates vom 29. Dezember 1957 (Auszug) 228

\section{KAPITEL XXVIII}

\section{Die Anderung des Besatzungsstatuts in West-Berlin vom Mai 1955}

187. Erklärung der Außenminister der drei Westmächte vom 23. Oktober 1954 über die Grundsätze der künftigen Anwendung des Berlin-Statuts . . . . . . . . . 228

188. Erklärung der Alliierten Kommandantur der Stadt Berlin vom 25. November 1954 über die Abänderung der Grundsatzerklärung vom 7. März 1951 . . . . . 229

189. Schreiben der Alliierten Kommandantur der Stadt Berlin vom 4. Mai 1955 über die Modifikation des Besatzungsregimes in Berlin (BKC/L [55] 1) . . . . . . 230

190. Proklamation der Alliierten Hohen Kommission von 5. Mai 1955 über dic Auflösung der Alliierten Hohen Kommission . . . . . . . . . . . . . 230

191. Proklamation der Bundesregicrung zum Tag der Souvcränität am 5. Mai 1955 . 231

192. Bekanntmachung des Zivilen Luftamtes der Alliierten Hohen Kommission vom 5. Mai 1955 zur Obernahme ziviler Luftfahrtangelegenheiten durd dic Bundesbehörden (Auszug) . . . . . . . . . . . . . . . 232

193. Schrciben der Alliierten Kommandantur der Stadt Berlin vom 5. Mai 1955 über die Ausübung der Verantwortliakeiten der Alliicrten Hohen Kommission (BKC/L [55] 2) . . . . . . . . . . . . . . . . . 232

194. Erklärung der Alliierten Kommandantur der Stadt Berlin vom 5. Mai 1955 über die Stellung West-Berlins nach dem Inkrafttreten der Pariser Verträge . . . . . 233

A. Scheiben rom 5. Mai 1955 (BKC/L [55] 3) . . . . . . . . . . . . . . . 233

B. Erklärung über Berlin vom 5. Mai 1955 . . . . . . . . . . . . . . 233

195. Sdhreiben der Alliierten Kommandantur der Stadt Berlin vom 14. Mai 1955 über Verfahrensänderungen nach der Berlin-Erklärung (BK/O [55] 10) . . . . 236

\section{KAPITEL XXIX}

Berlin und die Neuordnung der Bezielunngen der DDR zur östlidhen Welt im Warschauer Pakt, im Moskauer Vertrag und im Truppenvertrag

\section{Absdmitt: Der Warsdjauer Pakt}

196. Erlaß des Präsidiums des Obersten Sowjets vom 25. Januar 1955 über die Beendigung des Kricyszustandes zwischen der Sowjetunion und Dettschland (Auszug) . . . . . . . . . . . . . . . . . . . . 237

197. Die Ergebnisse der Warschauer Konferenz vom 11. bis 14. Mai 1955 . . . . . . 238

A. Das Schlußkommuniqué vom 14. Mai 1955 (Auszug) . . . . . . . . . . . 238

B. Erklärung Grotewohls bei der Unterzeidnung des Vertrags im Namen der Regierung der Deutschen Demokratischen Republik . . . . . . . . . 238

\section{XXII}


C. Vertrag über Frcundschaft, Zusammenarbeit und gegenseitigen Beistand zwischen der Volksrepublik Albanien, der Volksrepublik Bulgarien, der Ungarisdıen Volksrepublik, der Deutschen Demokratischen Republik, der Volksrepublik Polen, der Rumänischen Volksrepublik, der Union der Sozialistischen Sowjetrepubliken und der Tschechoslowakisctien Republik vom

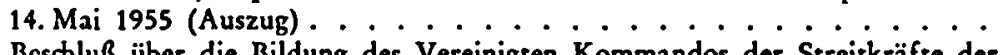

D. Beschluß über die Bildung des Vereinigten Kommandos der Streitkräfte der Teilnehmerstaaten des Vertrages über Freundschaft, Zusammenarbeit und gegenseitigen Beistand vom 14. Mai 1955 (Auszug) . . . . . . . . . 239

2. Abschnitt: Der Moskauer Vertrag

198. Moskauer Vertrag vom 20. September 1955 über die Bezichungen zwischen der DDR und der Sow jetunion (Auszug) . . . . . . . . . . . . 239

199. Schreiben des Außenministers der DDR, Dr. Lothar Bolz, an den Außenminister der Sowjetunion, W. A. Sorin, vom 20. September 1955 über die Kontrolle der DDR und der Verbindungswege nach Berlin . . . . . . . . . . . . 240

200. Beschluß des Ministerrats der Sowjetunion vom 20. September 1955 über die Auflösung der Hohen Kommission in Deutschland (Auszug) . . . . . . . . . 241

201. Mitteilung des Ministerpräsidenten der DDR vom 9. Dezember 1955 über Bewachung und Kontrolle der Staatsgrenzen der DDR durch die Deutsche Grenzpolizei

3. Alschnitt: Proteste der drei Westmächte gegen die Ubertragung von Rechten durch die Sowjetunion an die $D D R$, die sich aus Viermächtevereinbarungen berleiten

202. Erklärung der Außenminister der drei Westmächte in New York vom 28. September 1955 zu den Vereinbarungen zwischen der Sowjetunion und der DDR . 242

203. Note der drei Westmähte an die Sowjetunion vom 3. Oktober 1955 über die Abkommen und Vereinbarungen über das Deutschlandproblem . . . . . . . 243

204. Note der Sowjetunion vom 18. Oktober 1955 an die Westmähte über die Úbertragung von Hoheitsrechten an die DDR (Auszug) . . . . . . . . . . 243

205. Note der Botschaft der Vereinigten Staaten an dic Regierung der Sowjetunion vom 27. Oktober 1955 . . . . . . . . . . . . . . . . . . . . . . . . . 244

206. Senatsbeschluß Nr. 1289/55 vom 30. November 1955 zum Viermächte-Status von Berlin . . . . . . . . . . . . . . . . . . . 244

207. Notenwechsel 2wischen dem Botschafter der Vereinigten Staaten bei der Bundesrepublik und dem Botschafter der Sowjetunion bei der DDR über die Rechte der Westmächte in Berlin und die Verpflichtungen der Sowjetunion aus den Viermächtevereinbarungen ................ . 245

A. Note der Botschaft der Vereinigten Staaten vom 1. Dezember 1955 . . . . 245

B. Note der Botschaft der Sowjetunion vom 14. Dezember 1955 . . . . . . . 246

208. Briefwechsel zwischen der Botschaft der Sowjetunion bei der DDR und der Botschaft der Vereinigten Stazten bei der Bundesrepublik über die Lufthoheit über dem Gebiet der DDR . . . . . . . . . . . . . . . . . . 247

A. Schreiben der Botschaft der Vereinigten Staaten vom 18. Januar 1958 . . . . 247

B. Schreiben der Botschaft der Sowjetunion vom 28. Januar 1958 . . . . . . . 248

4. Abschnitt: Der Truppenvertrag der DDR

209. Gemeinsame Erklärung der Regierungen der Sowjetunion und der DDR vom 7. Januar 1957 in Moskau (Auszug) . . . . . . . . . . . . 249

210. Vertrag über die zeitweilige Stationierung sowjetischer Streitkräfte in der DDR vom 12. März 1957 (Auszug) . . . . . . . . . . . . . . . 249 


\section{KAPITEL XXX}

\section{Die Einglicderung Ost-Berlins in den Staatsapparat der DDR 1955-1958}

211. Bekanntmachung des Beschlusses des Magistrat von Groß-Berlin (Ost) über die erstc Anordnung zur Ausarbeitung des Volkswirtschaftsplanes 1956 vom 19. April 1955

212. Anweisung des Magistrats von Groß-Berlin (Ost) vom 15. Februar 1956 zur Sicherung von Ordnung und Stetigkeit im Erzichungs- und Bildungsproze $B$ der demokratischen Schule (Auszug) . . . . . . . . . . . . . . . . . 251

213. Bekanntmachung des Beschlusses des Magistrats von Groß-Bcrlin (Ost) zur Veränderung der staatspolitiscien Schulung in den Organen der Staatsverwaltung vom 2. März 1956 . . . . . . . . . . . . . . . . . . . . . . . . . . . 252

214. Besdiluß des Ministerrats der DDR zur Veränderung der staatspolitischen Schulung in den Organen der Staatsverwaltung vom 12. Januar 1956 (Auszug) . . . 252

215. Gesetz der Volksvertretung von Groß-Berlin (Ost) zur Ubernahme des Gesetzes über die örtlichen Organe der Staatsmacht vom 28. Januar 1957 . . . . . . . 25

216. Beschluß der Volksvertretung von Groß-Berlin (Ost) über die Anwendung des Gesetzes der Volkskammer der DDR über die Rechte und Pflichten der Volkskammer gegenüber den örtlichen Volksvertretungen vom 28. Januar 1957 . . . 270

217. Gesetz der Volksvertretung von Groß-Berlin (Ost) über die Wahlen zur Stadtverordnetenversammlung von Groß-Berlin und zu den Bezirksverordnetenversammlungen vom 11. April 1957 (Auszug) . . . . . . . . . . . . . 273

218. Beschluß der Stadtverordnetenversammlung von Groß-Berlin (Ost) vom 15. Mai 1957 über die Aufgaben des Volkswirtschaftsplanes 1957 (Auszug) . . . . . . 274

219. Beschluß der Stadtverordnetenversammlung von Groß-Berlin (Ost) über den zweiten Fünfjahrplan vom 22. Januar 1958 (Auszug) . . . . . . . . . . 275

220. Beschluß der Stadtverordnetenversammlung von Groß-Berlin (Ost) vom 22. Januar 1958 über den Volkswirtschaftsplan 1958 (Auszug) . . . . . . . . 275

221. Verordnung des Ministerrats der DDR über die Organisation der Planung der Volkswirtschaft vom 13. Februar 1958 (Auszug) . . . . . . . . . . . . . 276

222. Verordnung des Magistrats von Groß-Berlin (Ost) vom 14. Februar $195 \mathrm{~S}$ über die Anwendung des Gesetzes über die Vervollkommnung und Vereinfachung der Arbeit des Staatsapparates in der DDR . . . . . . . . . . . . . 277

223. Verordnung des Magistrats von Groß-Berlin (Ost) über den Außenhandel der DDR vom 14. März 1958 (Auszug) . . . . . . . . . . . . . . . . . . . . 282

224. Rede des Ost-Berliner Bürgermeisters W. Schmidt vom 15. März 1958 (Auszug) . 283

225. Verordnung des Magistrats von Groß-Berlin (Ost) über Wirtschaftsrat und Plankommissionen vom 31. März 1958 (Auszug) . . . . . . . . . . . . . . . . 284

226. Beschluß der Stadtverordnetenversammlung von Groß-Berlin (Ost) über Grundsätze und Maßnahmen zur Durchführung des Gesetzes über die Vervollkommnung und Vereinfachung der Arbeit des Staatsapparates in Berlin vom 9. April 1958 (Auszug) .................. . 285

227. Anordnung des Magistrats von Groß-Berlin (Ost) über die Zusammenfassung des Staatsplanes 1958 und des 2. Fünfjahrplanes vom 28. April 1958 (Auszug) . . . 286

228. Beschluß der Stadtverordnetenversammlung von Groß-Berlin (Ost) zur Ausarbeitung des Volkswirtschaftsplanes 1959 vom 2. Juli 1958 . . . . . . . 287

229. Direktive der Stadtverordnetenversammlung von Groß-Berlin (Ost) zur Ausarbeitung des Volkswirtschaftsplanes 1959 vom 2. Juli 1958 (Auszug) . . . . . 288 
230. Ausführungen W. Ulbrichts auf dem V. Partcitag der SED am 10. Juli 1958 über die Rolle Berlins als Hauptstadt der DDR (Auszug) . . . . . . . . . . . . 289

231. Anordnung Nr. 1 des Magistrats von Groß-Bcrlin (Ost) über die Aufstellung des Staatshaushaltsplanes für 1958 vom 31 . Juli $1958 \ldots$. . . . . . . . . . . . . 289

232. Gesetz über die Wahlen zur Volkskammer der DDR vom 24. September 1958 (Auszug) . . . . . . . . . . . . . . . . . . . . . 291

233. Beschluß der Stadtverordnetenversammlung von Groß-Berlin (Ost) vom 27. September 1958 über dic Vorbereitung der Wahlen zur Stadtverordnetenversammlung (Auszug) . . . . . . . . . . . . . . . . . . . . . . . . . . 292

234. Beschluß des Ministerrats der DDR über das Statut der Zentralen Kommission für Staatliche Kontrolle vom 16. Oktober 1958 (Auszug) . . . . . . . . . . 293

235. Rede des stellvertretenden Ministerpräsidenten W. Ulbricht am 27. Oktober 1958 in Berlin über dic Stellung Berlins als Hauptstadt der DDR (Auszug) . . . . . 295

\section{KAPITEL XXXI}

Dic Ankündigung der Berliner Krise durdh den sowjetischen Ministerpräsidenten Chrusditschow

236. Ansprache des sow jetischen Ministerpräsidenten N. S. Chruschtschow am 10. November 1958 in Moskau (Auszug) . . . . . . . . . . . . . . . . 296

237. Erklärung eines Sprechers des britischen Außenministeriums vom 10. November 1958 zur Chruschtschow-Rede (Auszug) . . . . . . . . . . . . 299

238. Erklärung der Bundesregicrung zum Viermächte-Status Berlins vom 12. November 1958 . . . . . . . . . . . . . . . . . . . . . . . . . . . 299

239. Erklärung des amerikanischen Außenministeriums vom 13. November 1958 zur Chruschtschow-Rede . . . . . . . . . . . . . . . . . 300

240. Kommunique über das Treffen des Bundeskanzlers mit General de Gaulle am 26. November 1958 in Bad Kreuznach (Auszug) . . . . . . . . . . . . . 301

\section{KAPITEL XXXII}

Die Noten der Sowjetunion vom 27. November 1958 zur Lage Berlins

241. Note der Regierung der Sowjetunion an die Regierung der Vereinigten Staaten von Amerika vom 27. November 1958 zur Lage Berlins . . . . . . . . . . 301

242. Note der Regierung der Sowjetunion an die Bundesregierung vom 27. November 1958 zur Lage Berlins . . . . . . . . . . . . . . . . . . . . . 319

243. Note der Regierung der Sowjetunion an die Regierung der DDR vom 27. November 1958 zur Lage Berlins . . . . . . . . . . . . . . . . . . . . 328

244. Erklärung der Volkskammer der DDR vom 3. Dezember 1958 über die Lage Berlins ..................... 335

245. Erklärung des Regierenden Bürgermeisters von Berlin, Willy Brand, vom 27. November 1958 zur sowjetischen Berlin-Note . . . . . . . . . . . . . 335

246. Aufruf von Persönlidikeiten des Berliner Offentliden Lebens vom 30. November 1958 zu den Wahlen in West-Berlin am 7. Dezember $1958 \ldots \ldots 336$

247. Erklärung der drei Westmächte und der Bundesrepublik vom 14. Dezember 1958 zur Berlin-Frage . . . . . . . . . . . . . . . . . 337

248. Erklärung des Nordatlantikrats rom 16. Dezember 1958 in Paris zur Berlin-Frage 338 


\section{KAPITEL XXXIII}

Dic Antwort der drei Westmäclte, der Bundesrepublik und der DDR auf die Noten der Sowjetunion zur Lage Berlins

249. Note der Regierung der Vercinigten Staaten von Amerika vom 31. Dezember 1958 an die Regierung der Sowjetunion zur Lage Berlins . . . . . . . . . . . 339

250. Note der Regicrung der Französischen Republik vom 31. Dezember 1958 an die Regicrung der Sowjetunion zur Lage Berlins . . . . . . . . . . . . . . 343

251. Note der Regierung Großbritanniens vom 31. Dezember 1958 an die Regierung der Sowjetunion zur Lage Berlins . . . . . . . . . . . . . . . 346

252. Note der Bundesregierung vom 5. Januar 1959 an die Regierung der Sowjetunion zur Lage Berlins . . . . . . . . . . . . . . . . . . . 353

253. Note der Regierung der DDR vom 7. Januar 1959 an die Regierung der Sowjetunion zur Lage Berlins . . . . . . . . . . . . . . . . . . 363

\section{KAPITEL XXXIV}

Der sowjetische Fricdenswertragsentwurf und dic Vorbereitung der Genfer Außenminister-Konferenz 1959

254. Entwurf der sowjetisdien Regierung für einen Friedensvertsag mit Deutschland vom 10. Januar 1959 (Auszug) . . . . . . . . . . . . . . . . . 372

255. Note der sowjetischen Regierung an die amerikanische Regierung vom 10. Januar 1959 betr. cinen Friedensvertrag für Deutschland (Auszug) . . . . . . . . . 372

256. Note der amerikanischen Regierung an die sowjetische Regierung vom 16. Februar 1959 (Auszug) ...................... 375

257. Note der sowjetischen Regierung an die amerikanische Regicrung rom 2. März 1959 (Auszug) . . . . . . . . . . . . . . 376

258. Rede von Ministerpräsident Nikita S. Chruschtschow in Berlin vom 9. März 1959 mit einer Stellungnahme zur Frage einer alle vier Sektoren umfassenden Freien Stade Berlin (Auszug) . . . . . . . . . . . . . . . 378

259. Gemeinsames Kommuniqué über den Besuch des sowjetischen Ministerpräsidenten, Nikita S. Chruschtschow, in Ost-Berlin vom 4. bis zum 12. März 1959 (Auszug) - 378

260. Rede des französischen Staatspräsidenten, Charles de Gaulle, vom 25. März 1959 auf einer Pressekonferenz (Auszug) . . . . . . . . . . . . . . 379

261. Kommuniqué der Tagung des Ministerrats der NATO in Washing̣ton rom 2. bis

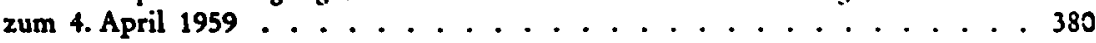

262. Schlufkommunique der Konferenz der Außenminister der Ostblodkstanten in Warschau vom 28. April 1959 (Auszug) . . . . . . . . . . . 3S1

\section{KAPITEL XXXV}

Die Bcrlin-Frage auf der Genfer Außenministerkonferenz

(11. Mai - 20. Juni und 13. Juli - 5. August 1959)

263. Westlicher Friedensplan vom 14. Mai 1959 (Auszug) . . . . . . . . 382

264. Erklïrung des sowjetischen Außenministers, Andrej A. Gromyko, vom 19. Mai 1959 zur Position der Westmächte in der Frage des Friedensvertrages mit Deutschland (Auszug) . . . . . . . . . . . . . . . . . 383

\section{XXVI}


265. Erklärung des sowjetischen Außenministers, Andrej A. Gromyko, vom 20. Mai 1959 (Auszug) . . . . . . . . . . . . . . . . . 384

266. Erklärung des französisdien Außenministers Maurice Couve de Murvilic, vom 22. Mai 1959

267. Erklärung des amerikanischen Außenministers, Christian A. Herter, bei der Unterbreitung des westlichen Wiedervereinigungsplans für Groß-Berlin am 26. Mai 1959

268. Erklärung des sowjetischen Außenministers, Andrej A. Gromyko, vom 10. Juni 1959 (Auszug) . . . . . . . . . . . . . . 396

269. Erklärung des amerikanischen Außenministers, Christian A. Herter, vom 10. Juni 1959 (Auszug) ................... . . 400

270. Berlin-Vorschlag der Westmächte vom 16./17. Juni 1959 . . . . . . . . . 402

271. Erklärung des amerikanischen Außenministers, Christian A. Herter, vom 20. Juli 1959 (Auszug)

272. Erklärung des sowjetischen Außenministers, Andrej A. Gromyko, vom 20. Juli 1959 (Auszug)

\section{KAPITEL XXXVI}

Die Fortsetzung des Meinungsaustauschs über Berlin 1959-1961

273. Kommuniqué vom 27. September 1959 über die Besprechungen zwischen Präsident Eisenhower und Ministerpräsident Chruschtschow in Camp David (Auszug) . . 406

274. Rede des sowjetischen Ministerpräsidenten, Nikita S. Chruschtschow, in Moskau nach seiner Rückkehr aus den Vereinigten Staaten am 28. September 1959 (Auszug) 406

275. Pressekonferenz Präsident Eisenhowers in Washineton am 28. September 1959 (Auszug) . . . . . . . . . . . . . . . . . . . 407

276. Sow jetische Erläutcrungen zur Bcrlin-Frage vom 13. Januar 1960 (Auszug) . . . 408

277. Rede des sowjecischen Ministerpräsidenten, Nikita S. Chruschtschow, in Baku vom 25. April 1960 (Auszug) . . . . . . . . . . . . . . . . . . . . . . 411

278. Memorandum der sowjetischen Regierung an die Bundesregierung vom 17. Februar 1961 (Auszug) . . . . . . . . . . . . . 412

279. Memorandum der sowjetischen Repierung vom 4. Juni 1961 zur DeutschlandFrage (Auszug) . . . . . . . . . . . . . . . . . . 413

280. Rundfunk- und Fernschansprache des sowjetischen Ministerpräsidenten, Nikita S. Chruschtsdiow, vom 15. Juni 1961 über scin Gespräch mit Präsident Kennedy in Wien (Auszug) . . . . . . . . . . . . . . . . . 416

281. Pressekonfercnz von Walter Ulbricht vom 15. Juni 1961 (Auszug) . . . . . 417

282. Antwortnote der Bundesregierung vom 12. Juli 1961 auf das sowjetische Memorandum vom 17. Februar 1961 (Auszug) . . . . . . . . . . . . . 423

283. Antwortnote der amerikanischen Regierung vom 17. Juli 1961 auf das sowjetische Memorandum vom 4. Juni 1961 (Auszug) . . . . . . . . . . . . . 424

284. Note der sowjetischen Regierung an die amerikanische Regierung vom 3. August 1961 (Auszug) ................... . . . .

285. Kommuniqué vom 6. August 1961 über die Beratungen der Ersten Sekretäre der ZK der kommunistischen und Arbeiterparteien der Teilnehmerstazten des Warschauer Paktes vom 3. bis zum 5. August 1961 in Moskau (Auszug) . . . . . . 430 


\section{KAPITEL XXXVII}

Die Diskussion über die Verbindungslinien zwisdsen Berlin und Westdeutschland und die Stellung Berlins zum Bund 1959-1960

286. Note der sowjetischen Regierung an die amerikanische Regierung vom 4. April 1959 betr. die Berliner Luftkorridore . . . . . . . . . . . . . . . . . . 4

287. Note der amerikanischen Regierung an die sowjetische Regierung vom 13. April 1959 betr. die Berliner Luftkorridore . . . . . . . . . . . . . . . . . . 43

288. Noten der sowjetischen Regierung an die Regierungen der drei Westmähte und der Bundesrepublik vom 11. und 13. November 1959 betr. Deutschlandfunk . . 434

289. Note der Bundesregicrung an die sowjetische Regierung vom 15. Dezember 1959 betr. Deutschlandfunk . . . . . . . . . . . . . . . . 4436

290. Note der amerikanischen Regierung an die sowjetische Regierung vom 15. Dezember 1959 betr. Deutshlandfunk . . . . . . . . . . . . . . . . . 437

291. Erklärung des Regierenden Bürgermeisters von Berlin, Willy Brandt, vor dem Abgcordnetenhaus vom 7. Januar 1960 (Auszug) . . . . . . . . . . 438

292. Erklärung des Regierenden Bürgermeisters von Berlin, Willy Brandt, vor dem Abgeordnetenhaus vom 11. Januar 1960 (Auszug) . . . . . . . . . . . . . 440

293. Rede von Bundesprïsident Heinrich Lübke im Schöneberger Rathaus vom 27. Januar 1960 (Auszug) . . . . . . . . . . . . . . . . 441

294. Note der sowjetischen Regierung an die Regierungen der drei Westmähte vom 30. Juni 1960 betr. die Rekrutierung von Berlinern für die Bundeswehr . . . . 442

295. Note der sowjetischen Regicrung an die Regierungen der drei Westmähte vom 28. Juli 1960 betr. Deutschlandfunk . . . . . . . . . . . . . . . . . . . 444

296. Note der amerikanischen Regierung an die sowjetische Regierung vom 12. August 1960 betr. die Rekrutierung von Berlinern für die Bundeswehr . . . . . . 445

297. Note der amerikanischen Regierung an die sowjetische Regierung vom 8. September 1960 betr. Deutschlandfunk . . . . . . . . . . . . . . . . . 446

\section{KAPITEL XXXVIII}

Die Einfïbrung von Reisebcschränkungen durds sowjetzonale Bebörden im August und September 1960

298. Anordnung des Innenministeriums der DDR vom 29. August 1960 über die Sperrung des Ostsektors von Berlin für die Zeit vom 31. August bis 4. September 1960

299. Erklärung der Regierung der DDR vom 29. August 1960 (Auszug) . . . . . . 448

300. Gemeinsame Erklärung der drei westlichen Botschafter in Bonn vom 3. September 1960 ... . . . . . . . . . . . . . . . . . 440 450

301. Anordnung des Innenministeriums der DDR vom S. September 1960 über die unbefristete Sperrung des Ostsektors von Berlin . . . . . . . . . . . 451

302. Note der Regierungen der drei Westmächte an die sowjetische Regierung vom 12. September 1960 . . . . . . . . . . . . . . . . . . . 451

303. Beschluß der Regierung der DDR vom 13. September 1960 über die Nichtanerkennung der von der Bundesrepublik für Einwohner West-Berlins ausgestellten Reisepässe . . . . . . . . . . . . . . . . . . . . . . . . . 4

\section{XXVIII}


304. Anordnung des Innenministeriums der DDR vom 13. September 1960 über die Nichtanerkennung der von der Bundesrepublik für Einwohner West-Berlins ausgestcllten Reiscpässe . . . . . . . . . . . . . . . . . . . . . .

305. Kommuniqué über die Sitzung der Bundesrcgierung am 14. September 1960 (Auszug)

306. Mitteilung der sowjetischen Botschaft in Ost-Berlin vom 15. September 1960 über die Nichtanerkennung der von der Bundesrepublik für Einwohner West-Berlins ausgestellten Reisepässe

307. Note der sowjetischen Regicrung an die Regierungen der drei Westmächte vom 26. September 1960 (Auszug)

308. Note der Regierungen der drei Westmächte an die sowjetische Regierung vom 26. Oktober 1960

\section{KAPITEL XXXIX}

\section{Die Eingliederung Ost-Berlins in den Staatsapparat der DDR 1959-1962}

309. Beschluß der Stadtverordnetenversammlung von Ost-Berlin über den Volkswirtschaftsplan 1959 vom 2. Februar 1959 (Auszug) . . . . . . . . . . . . . . 457

310. Verordnung über das Dienstsiegel der staatlichen Organe - Sicgelordnung vom 2. März 1959 . . . . . . . . . . . . . . . . . . . . . . . . . . . 458

311. Anordnung über die Allgemeinen Bedingungen für Lieferungen und Leistungen an die bewaffneten Organe der DDR vom 27. November 1959 . . . . . . . 459

312. Anordnung über die Zuständigkeit der Ministerien auf dem Gebiete der Preisbildung vom 21. März 1960 . . . . . . . . . . . . . . . . . . . . . .

313. Beschluß der Stadtverordnetenversammlung von Ost-Berlin über dic weitere Festigung der sozialistischen Gesetzlidkeit und inneren Ordnung und Sicherheir bei der Lösung der Aufgaben des Siebenjahrplanes vom 8. Dezember 1960 (Auszug) 460

314. Erlaß des Staatsrats der DDR zu den Ordnungen über die Aufgaben und die Arbeitsweise der örtlichen Volksvertretungen und ihrer Organe vom 28. Juni 1961462

315. Erlaß des Staatsrats der DDR zu den Ordnungen über die Aufgaben und dic Arbeitsweise der Stadtverordnetenversammlungen und der Stadtbezirksversammlungen und ihrer Organe in Berlin und den Stadtkreisen mit Stadtbezirken vom 7. Seprember 1961 . . . . . . . . . . . . . . . . . 462

316. Die Einbeziehung Ost-Berlins in die Verteidigungsmaßnahmen der DDR . . . 463

A. Verordnung zur Obernahme des Verteidigungsgesetzes, des Wehrpflichtgesetzes, des Militärstrafgesetzes und der Gesetze zur Ergänzung des Gerichtsverfassungsgesetzes und des Gesetzes über die Staatsan waltschaft vom 26. Januar 1962463

B. Bekanntmachung vom 1. Februar 1962 über die Erfasung für den aktiven Wehrdienst (Auszug) .............. . 463

\section{KAPITEL XI}

Die Absperrung des Ostsektors von Berlin im August 1961

317. Beschluß des Magistrats von Ost-Berlin über Arbeitsrechtverhältnisse in WestBerlin vom 4. August 1961 . . . . . . . . . . . . . . . 464

318. Erste Anordnung zur Durchführung des Magistratsbeschlusses vom 4. August 1961 über Zahlungen durch Personen, die in West-Berlin einer Beschäftigung nachgehen, rom 8. August 1961 . . . . . . . . . . . . . . . . 465 
319. Beschluß des Ministerrats der DDR vom 12. August 1961 über Maßnahmen zur Sperrung der Sektorgrenze von Berlin . . . . . . . . . . . . . . . . 466

320. Erklärung der Staaten des Warschauer Paktes über MalBnahmen zur Sperrung der Scktorgrenze von Bcrlin . . . . . . . . . . . . . . . 468

321. Bekanntmadiung des Ministeriums des Innern der DDR vom 12. August 1961 . . 470

322. Bekanntmachung des Ministeriums für Verkchrswesen der DDR vom 12. August 1961 . . . . . . . . . . . . . . . . . . 4 471

323. Bekanntmachung des Magistrats von Ost-Berlin vom 12. August 1961 über Beschäftigung in West-Berlin . . . . . . . . . . . . . . . 473

324. Bekanntmachung des Ministeriums des Innern der DDR vom 14. August 1961 . . 473

325. Bekanntmachung des Magistrats von Ost-Berlin vom 19. August 1961 über die Registricrung von Shülern, Lehrlingen und Studenten, die bisher in West-Berlin lernten ...................... 474

326. Bekanntmachungen des Ministeriums des Innern der DDR rom 22. August 1961, betr. Aufenthaltsgenehmigung für West-Berliner . . . . . . . . . . . . 474

\section{KAPITEL XLI}

Die Reaktionen auf die Absperrung des Ostsektors von Berlin

327. Rede des Regierenden Bürgermeisters, Willy Brandt, vom 13. August 1961 vor dem Abgeordnetenhaus von Berlin (Auszug) . . . . . . . . . . . 475

328. Kommuniqué über ein Gespräch zwischen Bundeskanzler Adenauer und dem sowjetischen Botschafter in Bonn, A. A. Smirnow, vom 16. August 1961 . . . . 478

329. Schreiben des Regierenden Bürgermeisters, Willy Brandr, an den amerikanischen Präsidenten, John F. Kennedy, vom 16. August $1961 \ldots . . . . . . . .479$

330. Note der amerikanischen Regierung an die sowjetische Regierung vom 16. August 1961 ... . . . . . . . . . . . . . . . . . 4480

331. Note der sowjetischen Regierung an die amerikanische Regierung vom 18. August 1961 (Auszug)

332. Erklïrung von Bundeskanzler Konrad Adenauer vor dem Deutschen Bundestag vom 18. August 1961 . . . . . . . . . . . . . . . . . . . . . 483

333. Kommuniquł vom 18. August 1961 über die Verstärkung der amerikanischen Truppen in Berlin . . . . . . . . . . . . . . . . . . . 490

334. Erklärung des amerikanischen Vizepräsidenten, Lyndon B. Johnson, vor dem Abgeordnetenhaus von Berlin am 19. August 1961 (Auszug) . . . . . . . . 490

\section{KAPITEL XIII}

\section{Die Berlin-Frage auf der Konferenz der blockfreien Staaten in Belgrad 1961}

335. Memorandum der Bundesregierung vom 23. August 1961 an die Teilnehmerstaaten der Belgrader Konferenz blodsfreier Staaten . . . . . . . . . . . 493

336. 27-Punkte-Erklärung der Belgrader Konferenz blodkfreier Staaten vom 6. September 1961 (Auszug) . . . . . . . . . . . . . . . . .

337. Schreiben des amerikanischen Präsidenten, John F. Kennedy, an den Präsidenten von Mali, Modibo Keita, und den indonesischen Präsidenten, Acmed Sukarno, vom 13. September 1961 (Auszug) . . . . . . . . . . . . . . . . . . 495

338. Schreiben des sowjetischen Ministerpräsidenten, Nikitz S. Chruschtschow, an den indischen Premierminister, Jawaharlal Nehru, vom 16. September 1961 (Auszug) 496

\section{XXX}




\section{KAPITEL XLIII}

\section{Der wcitere Mcinungsaustausd über Berlin 1961-1962}

339. Kommuniqué vom 22. November 1961 über die Beratungen zwischen Bundeskanzler Konrad Adenauer und Präsident John F. Kennedy in Washington (Auszug) 497

340. Rede des Ersten Sekretïrs des ZK der SED, Walter Ulbricht, vom 23. November 1961 auf der 14. Tagung der SED (Auszug) . . . . . . . . . . . . 498

341. Interview des amerikanischen Präsidenten, John F. Kennedy, mit dem Chefredakteur der "Iswestija“, Alcxei Adschubej, vom 25. November 1961 (Auszug) 501

342. Entschließung Nr. 19 der Versammlung der Westcuropäischen Union vom 13. Dczember 1961 über das Berlin-Problem . . . . . . . . . . . . . 506

343. Kommuniqué der Tagung des Nordatlantikrats in Paris vom 13. bis zum 15. Dezember 1961 (Auszug) . . . . . . . . . . . . . . . . . . 506

344. Denkschrift der sowjectischen Regierung an dic Bundesregierung vom 27. Dezember 1961 zur Deutschland- und Berlin-Frage (Auszug) . . . . . . . . . . 508

345. Memorandum der Bundesregierung an die sowjetische Regierung vom 21. Februar 1962 (Auszug) . . . . . . . . . . . . . . . . 510

346. Rede des amerikanischen Justizministers, Robert F. Kennedy, vom 22. Februar 1962 in Berlin (Auszug) . . . . . . . . . . . . . . . . 513

347. Interview des amerikanischen Außenministers, Dean Rusk, vom 1. März 1962 (Auszug) ...................... . 514

348. Rede des sowjetischen Ministerpräsidenten, Nikita S. Chruschtschow, vom 16. März 1962 auf einer Wahlversammlung in Moskau (Auszug) . . . . . . . 515

349. Gemeinsame Erklärung des amerikanischen Außenministers, Dean Rusk, und des sowjerischen Außenministers, Andrej A. Gromyko, zum Abschluß ihrer Gespräche in Genf am 27. März 1962 . . . . . . . . . . . . . . . . . 515

350. Schreiben des sow jetischen Ministerpräsidenten, Nikita S. Chruschtschow, an den britischen Premierminister, Harald Macmillan, vom 13. April 1962 (Auszug) . . 516

351. Rundfunkansprache des Regierenden Bürgermeisters, Willy Brandt, vom 15. April 1962 (Auszug)

\section{KAPITEL XIIV}

Die Diskussion über den freien Zugang nach Berlin und die Stellung Berlins zum Bund 1961-1962

352. Note der sowjetischen Regierung vom 23. August 1961 an die Regierungen der drei Westmähte zur Frage der Luftkorridore nach Berlin . . . . . . . 520

353. Note der Regierungen der drei Westmähte an die sowjetische Regierung vom 26. August 1961 zur Frage der Luftkorridore . . . . . . . . . . . . . 521

354. Note der Regierung der DDR an die amerikanische Regierung vom 26. August 1961 betr. die Verstärkung der amerikanischen Truppen in Berlin . . . . . . 523

355. Note der sowjetischen Regierung an die Regierungen der drei Westmächte vom 2. September 1961 zur Frage der Luftkorridore (Auszug) . . . . . . . . 525

356. Note der Regierungen der drei Westmächte an die sowjetische Regierung vom 8. September 1961 zur Frage der Luftkorridore (Auszug) . . . . . . . . 527 
357. Rede des Regierenden Bürgernucisters, Willy Brandt, vor dem Deutschen Bundest.1\% vom 6. De\%ember 1961 (Auszug) . . . . . . . . . . . . . 530

358. Note der amerikanisthen Regierung an die sowjetische Regierung vom 15. Februar 1962 betr. den Verkelir in den Luitkurridoren . . . . . . . . . . . 532

359. Note der sowjetischen Regicrung an dic ancrikaniscte Regicrung vom 17. Februar 1962 betr. den Verkehr in den Luttkorridoren (Auszug) . . . . . . . . . 533

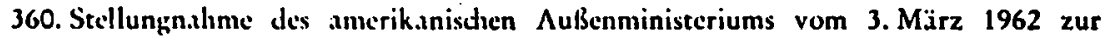
Frage cincr Intern.utionalisierung der Zugangswege nach Berlin . . . . . . . . 534

361. Rede von Parteisckretïr Walter Ulbricht vor dem ZK der SED vom 21. März 1962 (Auszug) . . . . . . . . . . . . . . . . 535

362. Zullgesetz der DUR vom 28. Mïz 1962 . . . . . . . . . . . . . . . 537

$\Lambda$. Erklärung der Reyierung der DDR vom 21. Jinuar 1962 (Auszug) . . . . . 537

B. Auntidie Begründung vom 24. Janu.ır 1962 zum Zollgesetz der DDR (Auszug) 537

C. Gesetz über das Zollwesen der Deutschen Demokratischen Republik vom 28. März 1962 (Auszug) . . . . . . . . . . . . . 539

\section{KAPITLL XIV}

\section{Die weitere Entwidklung der Diskussion um Berlin 1962-1966}

363. Pressekonferenz des amerikanischen Präsidenten, John F. Kennedy, vom 18. April 1962 (Auszug) . . . . . . . . . . . . . . . . 540

364. Beritht des suvjetisthen Aubenministers, Andrej A. Gromyko, vor dem Obersten Suwjet der UdSSR über den Stand der amerikanisch-sowjetiscten Sondierungen von 25. April 1962 (Auszug) . . . . . . . . . . . . . 541

365. Rede des sowjetiscten Ministerpräsidenten, Nikita S. Chruschtschow, vom 10. Juli 1962 vor dem Weltkongrel' für allgemeine Abrüstung und Frieden in Moskau (Auszug) . . . . . . . . . . . . . . . . . 542

366. Rede des Staatssckretürs des deutschen Auswärtigen Amtes, Karl Carstens, vor der Vers.ammlung der Westeuropäischen Union in P.ris vom 6. Dezember 1962 (Auszug) 543

367. Rede des suwjetisthen Ministerpräsidenten, Nikits S. Chruschtschow, vom 16. Januar 1963 vor dem VI. P.urtcitag der SED (Auszug) . . . . . . . . . . 54t

36S. Notenwectsel zwischen der Sowjetregierung und der Bundesregierung über die Geltung des deutsch-französisctien Vertrages vom 22. Januar 1963 für Berlin (Auszügc) . . . . . . . . . . . . . . . . 545

A. Sowjetisthe Note rom 5. Februar 1963 . . . . . . . . . . . 545

B. Note der Bundestegierung rom 29. März 1963 . . . . . . . . . . 546

C. Sowjetische Note vom 17. ML.xi 1963 . . . . . . . . . . . . . . . 547

369. Erklïrung des Regierenden Büryermeisters, Willy Brandt, vor dem Abgeordnetenhaus von Berlin vom 18. März 1963 (Auszug) . . . . . . . . . . . 548

370. Rede des amerikanisthen Prïsidenten, John F. Kennedy, in Berlin vor dem Rathaus Sthöneberg rom 25. Juni 1963 . . . . . . . . . . . . . 549

371. Rithtlinien der Reyierungspolitik, gebillige vom Abgeordnetenhaus von Berlin am 3. September 1963 (Auszug) . . . . . . . . . . . . . . . 551

372. Erklärung der Regierung der DDR vom 22. Juni $196+$ betr. den Luftverkehr nach West-Berlin .................. . . 552

373. Erklärung des amerikanischen Außenministeriums vom 23. Juni $196+$ betr. den Luftverkehr nach West-Berlin . . . . . . . . . . . . . 553

\section{XXXII}


374. Note der Sowjetregicrung an die Regierung der drei Westmächte vom 25. Juni 1964 betr. die Walhl des Präsidenten der Bundesrepublik Deutschland in West-Berlin . 553

375. Freundsctiafts- und Beistandspakt zwischen der Sowjetunion und der DDR vom 12. Juni 1964 (Auszug) . . . . . . . . . . . . . . . . 554

376. Deutschland-Erklärung der Drei Mächte vom 26. Juni 1964 (Auszug) . . . . . 556

377. Memorandum der Regierung der DDR vom 13. Juli 1964 zum Freundschafts- und Beistandspakt zwischen der Sowjetunion und der DDR (Auszug) . . . . . . 557

378. Erklärung der Sowjetregicrung vom 18. Juli 1964 (Auszug) . . . . . . . . 557

379. Erklärung der deutschen Bundesregierung vom 30. November 1964 zur Berechtigung, das Land Berlin in den Teststopp-Vertrag cinzubezichen . . . . . . 558

380. Entschließung Nr. 25 der Versammlung der Westeuropäischen Union vom 4. Dezember 1964 über die Berlin- und Deutschland-Frage . . . . . . . . . . 558

381. Note der sowjetischen Regierung an die amerikanische Regierung vom 23. März 1965 betr. Sitzung des Deutschen Bundestags in Berlin . . . . . . . . . 559

382. Note der amerikanischen Regicrung an die sowjetische Regicrung vom 7. April 1965 betr. Sitzung des Deutschen Bundestags in Berlin und Störung des Berlin-

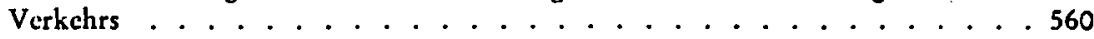

383. Erklärung des Präsidenten des Deutschen Bundestages, Eugen Gerstenmaier, zur Eröffnung der Plenarsitzung in Berlin am 7. April 1965 (Auszug) . . . . . 561

384. Kommuniqué über dic Ministertagung des Nordatlantikrats vom 14. bis zum 16. Dezember 1965 in Paris (Auszug) . . . . . . . . . . . . 562

385. Kommuniqué über dic Besprechung zwischen dem amcrikanischen Präsidenten, Lyndon B. Johnson, und dem deutschen Bundeskanzler, Ludwig Erhard, in Washington vom 20. bis zum 21. Dezember 1965 (Auszug) . . . . . . . . 563

386. Beschluß des Bundesverfassungsgerichts vom 20. Januar 1966 im Verfahren über die Verfassungsbeschwerde des Professors Ernst Nickisch, Berlin, gegen ein Urteil des Bundesgerichtshofs vom 29. November 1961 (Auszug) . . . . . . . . 563

\section{KAPITEL XLVI}

\section{Die Frage des innerstädtischen Verkehrs 1962-1966}

387. Interview des Vorsitzenden des Staatsrats der DDR, Walter Ulbricht, mit den sowjetischen Zeitungen "Prawda“ und "Izvestia" vom 29. April 1962 (Auszug) 568

388. Rede des Ersten Sekretärs des ZK der SED, Walter Ulbricht, vor dem VI. Parteitag in Ost-Berlin vom 15. Januar 1963 (Auszug) . . . . . . . . . . 569

389. Fernsehansprache des Vorsitzenden des Staatsrats der DDR, Walter Ulbricht, vom 8. Februar 1963 nAn die Bevölkerung von Westberlin" (Auszug) . . . . . 570

390. Erklärung des Regierenden Bürgermeisters, Willy Brandt, im Fernsehen und Rundfunk vom 15. Dezember 1963 . . . . . . . . . . . . 571

391. Protokoll über eine zeitweilige Regelung für den Verwandtenbesuch von WestBerlinern in Ost-Berlin vom 17. Dezember 1963 (Mantelprotokoll mit Anlage) . 572

392. Erklärung des Senatsrats Horst Korber anläßlich der Unterzeichnung des Protokolls vom 17. Dezember 1963 . . . . . . . . . . . . . 577

393. Erklärung des Regierenden Bürgermeisters, Willy Brandr, auf einer internationalen Pressekonferenz im Rathaus Schöneberg vom 17. Dezember 1963 (Auszug) . . 577

394. Gemeinsame Erklärung der Bundesregierung und des Senats von Berlin vom 17. Dezember 1963 . . . . . . . . . . . . . . . 578 
395. Bricf von Bundeskanzler Ludwig Erhard an den Regierenden Bürgermeister, Willy Brandt, vom 23. September 1964 . . . . . . . . . . . . . 578

396. Erklärung des Leiters des Presse- und Informationsamtes des Landes Berlin, Egon Balır, auf einer Pressckonferenz am 24. September 1964 (Auszug) . . . . . . . 579

397. Gemcinsame Erklïrung des Senats von Berlin und der Bundessegierung zur Unterzeidhnung einer weiteren Passierscheinübercinkunft am 25. November 1965 . . . 579

398. Erklärung des Leiters des Presse- und Informationsamtes des Landes Berlin, Egon Bahr, auf ciner Pressekonferenz am 7. März 1966 (Auszug) . . . . . . . . . 579

399. Protokoll über die Regelung des Verwandtenbesuchs von West-Berlinern in OstBerlin vom 7. Mürz 1966 . . . . . . . . . . . . . . . . . . . . . 580

400. Erklärung von Senatsrat Horst Korber nach der Unterzeichnung der Passierscheinübercinkunft am 7. März 1966 in Ost-Berlin . . . . . . . . . . . . . . 587

401. Gemeinsame Erklärung des Senats von Berlin und der Bundesregierung zur Unterzcichnung ciner weiteren Passierscheinübercinkunft am 7. März 1966 . . . . . 5s8

402. Gemeinsame Erklärung der Bundesregierung und des Senats von Berlin vom 29. Juli 1966 . . . . . . . . . . . . . . . . . . . . 589

403. Protokoll für Verwandtenbesuche in dringenden Familienangelegenheiten vom

6. Oktuber 1966 . . . . . . . . . . . . . . . . . . . . 589 